\title{
ANÁLISE DE UM PROJETO PEDAGÓGICO: FRACTAL E TEORIA DO CAOS PARA INTEGRAÇÃO DE CONTEÚDOS
}

\author{
ANALISIS DE UN PROYECTO PEDAGÓGICO: FRACTAL Y TEORÍA DEL CAOS \\ PARA INTEGRACIÓN DE CONTENIDOS
}

\section{ANALYSIS OF A PEDAGOGICAL PROJECT: FRACTAL AND CHAOS THEORY FOR INTEGRATING CONTENT}

\author{
Samara Régia de ANDRADE ${ }^{1}$ \\ Marianne Louise Marinho MENDE ${ }^{2}$ \\ Cristhiane Maria Bazílio de Omena MESSIAS ${ }^{3}$
}

RESUMO: A presente pesquisa buscou discutir os efeitos de um projeto pedagógico da área de Ciências da Natureza e Matemática, realizado em uma Escola de Educação Básica, em que foi utilizado o Estudo dos Fractais como eixo integrador das disciplinas. Como questionamento norteador da pesquisa tinha-se: Como se deu o desenvolvimento das práticas interdisciplinares no projeto e de que forma a mesma contribuiu para a contextualização do ensino, tornando-o significativo? Para a realização dos objetivos foram analisadas fontes documentais sobre o projeto escolar, além de ser realizada uma entrevista com docentes do Ensino Médio. Como resultados da pesquisa, a partir das entrevistas realizadas pelos professores, emergiram três categorias para discussão. Após análise dos resultados, considera-se que, embora seja desafiador trabalhar a integração das disciplinas, faz-se necessário assumir essa postura na prática docente, visto que possibilitará ao educando o desenvolvimento de competências capazes de responder às crises que a contemporaneidade estabelece.

Palavras chave: Integração de disciplinas. contextualização de conteúdos. práticas interdisciplinares.

PALAVRAS-CHAVE: Integração de disciplinas. Contextualização de conteúdo. Práticas interdisciplinares.

${ }^{1}$ Universidade de Pernambuco (UPE), Petrolina - PE - Brasil. Discente do programa de pós-graduação em Formação de Professores e Práticas Interdisciplinares. OrcID: https://orcid.org/0000-0002-6004-342X. E-mail: samararegia_2525@hotmail.com

${ }^{2}$ Universidade de Pernambuco (UPE), Petrolina - PE - Brasil. Doutora em Ciência e Tecnologia dos Alimentos. Professora Permanente do Programa de Pós-graduação Formação de Professores e Práticas Interdisciplinares (PPGFPPI). Professora Colaboradora do Programa de Pós-Graduação em Ciência e Tecnologia Ambiental para o Semiárido. Professora Adjunta do Colegiado de Nutrição. OrcID: https://orcid.org/0000-0003-1560-765X. Email: marianne.marinho@upe.br

${ }^{3}$ Universidade de Pernambuco (UPE), Petrolina - PE - Brasil. Doutora em Ciências. Professora Permanente do Programa de Pós-graduação Formação de Professores e Práticas Interdisciplinares (PPGFPPI). Professora Colaboradora do Programa de Pós-Graduação em Ciência e Tecnologia Ambiental para o Semiárido. Professora Adjunta do Colegiado de Nutrição. OrcID: https://orcid.org/0000-0002-1991-0376. E-mail: cristhiane.omenao@upe.br 
RESUMEN: La presente investigación buscó discutir los efectos de un proyecto pedagógico del área de Ciencias de la Naturaleza y Matemáticas, realizado en una Escuela de Educación Básica, en la que se utilizó el Estudio de los Fractrales como eje integrador de las disciplinas. Esta investigación fue desarrollada a partir del abordaje metodológico cualitativo y según los objetivos se trató de un estudio de caso. Como cuestionamiento orientador de la investigación se tenía: ¿Cómo se dio el desarrollo de las prácticas interdisciplinares en el proyecto y de qué forma la misma contribuyó a la contextualización de la enseñanza, haciéndolo significativo? Para la realización de los objetivos se analizaron fuentes documentales sobre el proyecto escolar, además de ser realizada una entrevista con docentes de la Enseñanza Media. Como resultados de la investigación, a partir de las entrevistas realizadas por los profesores, surgieron tres categorías para discusión: Concepciones de los profesores sobre la interdisciplinaridad, Interdisciplinaridad como principio orientador del proyecto analizado, La interdisciplinariedad para el aprendizaje significativo. Después del análisis final de los resultados, se considera que, aunque es desafiador trabajar la integración de las disciplinas, se hace necesario asumir esa postura en la práctica docente, ya que la misma posibilita al educando el desarrollo de competencias capaces de responder a las crisis que la contemporaneidad establecida.

PALABRAS CLAVE: Integración de disciplinas. Contextualización de contenidos. Prácticas interdisciplinares.

ABSTRACT: The present research sought to discuss the effects of a pedagogical project in the area of Natural Sciences and Mathematics, carried out in a School of Basic Education, in which the Study of the Fractals was used as the integrating axis of the disciplines. This research was developed from the qualitative methodological approach and according to the objectives it was a case study. As a guiding question of the research was: How was the development of interdisciplinary practices in the project and how did it contribute to the contextualization of teaching, making it meaningful? For the accomplishment of the objectives, documentary sources about the school project were analyzed, besides an interview with teachers of the High School. As a result of the research, from the interviews conducted by the teachers, three categories emerged for discussion: Conceptions of teachers on interdisciplinarity, Interdisciplinarity as guiding principle of the project analyzed, Interdisciplinarity for meaningful learning. After a final analysis of the results, it is considered that, although it is challenging to work on the integration of the disciplines, it is necessary to assume this position in the teaching practice, since it enables the student to develop skills capable of responding to crises that contemporaneity lays down.

KEYWORDS: Integration of disciplines. Contextualization of contents. Interdisciplinary practices.

\section{Introdução}

É lícito considerar que o arquétipo positivista de ensino, com base fragmentada de conteúdo, possui valores de um mundo construído entre os séculos XVI e XX. Embora outrora tenha sido bastante aceito e concernente no meio científico, pois trouxe resultados, atualmente entende-se que o avanço do conhecimento, os desafios do mundo globalizado no 
século XXI, além da própria complexidade humana exigem mudanças no campo educacional. Em respostas a tais mudanças, emerge a proposta da integração de conteúdos em vários níveis (pluri, inter e transdisciplinar), que oferece uma alternativa para a abordagem disciplinar atual, relatando a carência de interações disciplinares que permitam uma relação contextualizada, articulada entre as diferentes disciplinas, os problemas reais e o contexto social vivido pelo estudante.

Discussões sobre integração de conteúdos no campo da produção do conhecimento são tomadas de forma recorrente quando se pretende romper com abordagens cartesianas e positivistas nos processos de construção do conhecimento. Desse modo, busca-se ampliar a compreensão da própria ciência sob uma perspectiva mais integradora e menos fragmentária. No campo educacional, a integração de conteúdos em nível de interdisciplinaridade é um conceito frequentemente abordado em propostas pedagógicas de instituições públicas e privadas, sendo inclusive mencionada em documentos oficiais de órgãos governamentais responsáveis por regulamentar parâmetros e/ou diretrizes para a educação, como salientam as Diretrizes Curriculares Nacionais para o Ensino Médio (DCNEM) (BRASIL, 1999):

Nesta multiplicidade de interações e negações recíprocas, a relação entre as disciplinas tradicionais pode ir da simples comunicação de idéias até a integração mútua de conceitos diretores, da epistemologia, da terminologia, da metodologia e dos procedimentos de coleta e análise de dados. Ou pode efetuar-se, mais singelamente, pela constatação de como são diversas as várias formas de conhecer. Pois até mesmo esta "interdisciplinaridade singela" é importante para que os alunos aprendam a olhar o mesmo objeto sob perspectivas diferentes (MELLO, 1998, grifo do autor).

Assim, buscou-se nesse estudo discutir os efeitos de um projeto pedagógico que envolve integração de conteúdos em nível interdisciplinar, realizado em uma escola de Educação Básica. O referido projeto foi elaborado pelos professores da área de Ciências Naturais e Exatas da Escola Nossa Senhora do Santíssimo Sacramento (Sacramentinas), localizada em Senhor do Bonfim, no interior da Bahia, e tinha como objetivo principal possibilitar a aprendizagem significativa por meio de eixos temáticos integradores. Para conduzir essa pesquisa utilizou-se a seguinte questão norteadora: "Como se deu o desenvolvimento das práticas interdisciplinares no projeto e de que forma a mesma contribuiu para a contextualização do ensino, tornando-o significativo?"

Para possibilitar a integração dos conteúdos foi utilizado como eixo integrador o Estudo dos Fractais e da Teoria do Caos. A escolha de um eixo integrador seguiu o que está pressuposto nos documentos oficiais da educação: 
A interdisciplinaridade supõe um eixo integrador, que pode ser o objeto de conhecimento, um projeto de investigação, um plano de intervenção. Nesse sentido, ela deve partir da necessidade sentida pelas escolas, professores e alunos de explicar, compreender, intervir, mudar, prever, algo que desafia uma disciplina isolada e atrai a atenção de mais de um olhar, talvez vários (BRASIL, 2002, p. 88-89 grifo do autor).

A seguir apresenta-se uma abordagem histórica do pensamento complexo e sua associação à integração das disciplinas e, em seguida, uma breve revisão sobre a Geometria Fractal e a Teoria do Caos.

\section{Morin, o pensamento complexo e a integração das disciplinas}

Morin (2001), em seu texto Notas para um Emilio contemporâneo, faz uma alusão ao Emilio de Rousseau. O personagem original é uma metáfora dos programas de educação que poderiam preparar o aluno para a vida na sociedade civil. Na obra original, Rousseau infere o papel da educação para a formação integral do homem, não separando o natural do cultural e considerando a sensibilidade em detrimento da razão. Nesta mesma linha de pensamento, quando Morin (2001) refere-se ao Emílio contemporâneo, no prefácio de seu livro “A cabeça bem feita", o autor traz a ideia de que a educação deve religar os saberes fragmentados para a formação do homem capaz de enfrentar todas as situações complexas contemporâneas. Morin (2001) propõe a reforma do pensamento e das instituições com base em mudanças no sistema educacional para a formação do pensamento complexo e para o desenvolvimento da autonomia do pensamento do educando; o autor retoma a primeira finalidade do ensino, formulada por Montaigne na década de 1580: mais vale uma cabeça bem-feita que bem cheia.

A reforma do pensamento, proposta pelo filosofo, inclui a conversão de informações recebidas pelos alunos em conhecimento, através de ações que estimulem o pensamento reflexivo, a contextualização e a ligação entre os saberes adquiridos. Ou seja, nesse processo, considera-se conhecimento como a informação tratada e com atribuição de significados. Para Morin (2001), a organização estrutural atual do sistema educativo está fundamentada em divisões e superespecializações. Embora o autor reconheça as vantagens das separações das ciências, alerta para o risco de continuar apenas reduzido ao simples, separando o que está ligado, decompondo e não recompondo os saberes.

Esse pensamento que recorta, isola, permite que especialistas e experts tenham ótimo desempenho em seus compartimentos, e cooperem eficazmente nos setores não complexos de conhecimento, notadamente os que concernem ao funcionamento das máquinas artificiais; mas a lógica a que eles obedecem estende à sociedade e às relações humanas os 
constrangimentos e os mecanismos inumanos da máquina artificial e sua visão determinista, mecanicista, quantitativa, formalista; e ignora, oculta ou dilui tudo que é subjetivo, afetivo, livre, criador (MORIN, 2001, p. 15).

Na busca por um novo modelo para a Educação, Morin (2001) trata, em todos os seus livros, da questão da complexidade ou do pensamento complexo. Pode-se entender aqui complexo como "aquilo que é tecido em conjunto" e não pode ser reduzido a um simples dito ou conceito. Nesse sentido, pode-se inferir dos pensamentos de Morin a troca da visão reducionista pela visão complexa, sendo assim, a integração das disciplinas estaria ligada a este processo de reforma do pensamento com contextualização de informações e atribuição de significado. Compreendendo a importância das conclusões de Morin (2001) acerca da necessidade de mudanças no modelo educacional e como a integração de conteúdos pode estar associada a essa mudança, faz se mister ao profissional da educação contemporâneo empreender novas práticas escolares que tragam e/ou incitem a construção da visão e pensamento complexo.

\section{Geometria Fractal e Teoria do Caos}

Há mais de dois mil anos um matemático grego, chamado Euclides, empenhou-se em tentar provar, matematicamente, que todas as formas da natureza podiam ser reduzidas a formas geométricas simples: cubos, paralelepípedos, entre outros. Contudo, percebe-se que a natureza foge da regularidade das formas geométricas euclidianas. Montanhas não são formadas por cones, continentes não são circunferências e existem alguns comportamentos na natureza que fogem completamente da geometria euclidiana.

Este foi o ponto de partida para Benoit Mandelbrot ao estudar as irregularidades, matemático polonês que descobriu os fractais na década de 70. Os fractais são formas geométricas geradas a partir de fórmulas que retratam matematicamente a geometria da natureza, como o relevo do solo ou as ramificações de nossas veias e artérias. Estes fractais possuem, entre outras, uma propriedade especial de característica primordial, a autossimilaridade. Segundo Barbosa (2005), esses objetos podem ser comparados com cada uma de suas partes sem perder sua definição formal, ou seja, o todo é semelhante.

Por sua vez, a Teoria do Caos busca explicar fenômenos que não são previsíveis (nãolineares) e, por este motivo, considerados caóticos, pois não há como controlá-los. Segundo Gatti (2007), se a Teoria do Caos tem um pai, seu nome é Edward Lorenz. Em seus estudos, Benoit Mandelbrot observa que as equações de Lorenz se identificam com a própria definição dada por ele mesmo sobre os fractais. A associação do experimento de Lorenz com a 
matemática de Mandelbrot indica que o caos parece estar na essência de tudo, moldando o Universo. Segundo Mandelbrot, ele e Lorenz buscam a mesma verdade escondida no meio de uma grande montanha. A diferença é que escavam a partir de lugares diferentes.

\section{Metodologia}

Para a presente pesquisa de natureza qualitativa foram utilizadas abordagens, cujo foco principal é entender os sujeitos diante de seus respectivos contextos. A operacionalização desta pesquisa se processou através de análise documental, de observações realizadas diante do objeto estudado, e por entrevistas direcionadas aos sujeitos de pesquisa, neste caso os docentes envolvidos no projeto. $\mathrm{O}$ corpo de profissionais que aderiu à proposta de trabalho compreende cinco (05) professores licenciados em suas respectivas áreas de conhecimento: Ciências da Natureza e Ciências Exatas (Química, Física, Biologia e Matemática). Tais docentes foram convidados a participar da pesquisa pessoalmente pelo pesquisador. $\mathrm{O}$ convite pessoal foi formalizado no ambiente da Escola Lócus com o consentimento da direção. Aqueles que aceitaram o convite assinaram o Termo de Consentimento Livre Esclarecido.

Sendo assim, a entrevista realizou-se de forma individual com os docentes para efeito de melhor compreensão sobre o processo de aplicação do projeto interdisciplinar em questão na Escola-alvo. As atividades tiveram registro no período de 07 a 20 de maio de 2018. A entrevista, composta por 10 questões, articulou-se com perguntas "abertas" gravadas em áudio. Visando garantir o sigilo na pesquisa, os entrevistados foram nomeados como P1, P2, P3, P4, P5.

\section{Descrição do objeto de estudo}

O objeto de estudo dessa pesquisa se constitui na análise de um projeto pedagógico intitulado "A Ciência dos Padrões", da área de Ciências da Natureza e Exatas, elaborada pelos professores da Escola Sacramentinas em Senhor do Bonfim (BA). Tal projeto, no intuito de promover a integração de conteúdos, usou como eixo integrador o estudo da Geometria Fractal e da Teoria do Caos para melhor compreensão de fenômenos naturais. A equipe de professores envolvida no projeto optou por usar uma série, The Code, lançada em 2014, como recurso didático para explorar os temas do eixo integrador com os alunos. A série em caráter de documentário produzido para a BBC Two (British Broadcasting Corporation) no Reino Unido é atualmente transmitida pela Netflix (provedora global de filmes e séries de televisão 
via streaming). É uma produção dividida em três episódios, na qual o professor de matemática, Marcus du Sautoy, busca explicar o código matemático que está por trás da vida na Terra e de todo o universo. Para isto ele explora temas como a Geometria Fractal e a Teoria do Caos, dentre outros temas das áreas de Biologia, Física e Química e Matemática.

Embora o projeto tenha se expandido por todos os níveis de ensino da escola, o foco desta pesquisa se deu com os professores do Ensino Médio, mais precisamente das turmas de $1^{\circ}$ e $2^{\circ}$ anos. Sendo assim, o projeto analisado desenvolveu-se ao longo do ano 2017 da seguinte forma:

I trimestre: Nessa etapa, os alunos buscaram padrões na natureza para expor em sala de aula; tal representação ocorreu através de fotografias de formas geométricas, presentes em sua cidade, que geram padrões geométricos exatos e fractais. Essas fotografias foram expostas (apresentação em slide) aos respectivos professores das áreas envolvidas.

II trimestre: Os alunos interpretaram os padrões e figuras geométricas encontrados na etapa anterior (análise dos assuntos, disciplinas envolvidas e do impacto para a sociedade). Nesse processo de análise, os alunos apontaram as regras que geravam aqueles padrões, além de prever fenômenos possíveis a partir das aplicações dos padrões encontradas no trabalho anterior. Em seguida, eles apontaram os assuntos envolvidos nos itens anteriores referentes às disciplinas (Biologia, Química, Física e Matemática), e identificaram alguns sistemas caóticos em sua cidade. A culminância dessa etapa ocorreu com a apresentação, por parte dos alunos, de um seminário referente aos resultados analisados. Nesse momento, os professores puderam contribuir com os trabalhos dos alunos de forma conjunta, colaborando com o desenvolvimento da visão holística dos orientandos.

III trimestre: Fase final do projeto, momento em que os alunos apresentam os seus trabalhos na Mostra Científica.

\section{Resultados e discussão}

Este tópico apresenta a análise descritiva dos resultados obtidos a partir da análise documental, das observações obtidas mediante o objeto de estudo e das entrevistas aos sujeitos de pesquisa. 


\section{Observações ao objeto de estudo}

Algumas características observadas, pela pesquisadora nos professores participantes do projeto pedagógico analisado suscitam indícios de interdisciplinaridade, de acordo com alguns autores do campo epistemológico. Uma das características observadas foi, sem dúvida, atitude de inovação e coragem por parte desse grupo de professores (ao sair da zona de conforto de suas disciplinas) durante a elaboração e aplicação das etapas do projeto.

Diante da contraposição da ação com o referencial teórico, nos deparamos com Fazenda (1994, p. 28), ao explicar que interdisciplinaridade não é categoria de conhecimento, mas de ação. Baseada nessa compreensão, a autora menciona várias vezes que a interdisciplinaridade depende basicamente de uma atitude, de uma mudança de postura em relação ao conhecimento, "uma substituição da concepção fragmentária para a unidade do ser humano" (FAZENDA, 1994, p. 40). Na verdade, torna-se evidente a ênfase dada à ação do sujeito para que se promova uma transformação no conhecimento.

Assim, na elaboração da atividade pedagógica, destaca-se a postura (e ação) dos docentes que se demonstram dispostos ao diálogo ${ }^{4}$. Durante as várias reuniões ocorridas entre os professores, destaca-se a disposição dos mesmos para construir o trabalho coletivamente. Surge, nesse momento, o primeiro indício viável e possível de integração das disciplinas, mesmo em nível elementar. Pois, em busca da construção de uma visão holística de mundo, os docentes envolvidos no projeto deram abertura ao diálogo entre as disciplinas das quais cada um é representante.

Assim, ainda na busca por fundamentação epistemológica para essas características, encontramos em Fazenda (2011) a reflexão de que o pensar interdisciplinar reconhece que nenhuma forma de conhecimento é em si mesma racional. Por essa razão, o diálogo torna-se imprescindível e, além disso, no projeto interdisciplinar não se ensina e nem se aprende, mas vive-se e exerce-se. E como consequência dessa ação, obtém-se um produto final cuja ideia central se norteia por características como humildade, totalidade e intenção de inovação. Tais características, de acordo com Ferreira (2011), são pertinentes a um projeto interdisciplinar.

Além disso, foi possível observar alguns momentos que permeiam a possível concepção de interdisciplinaridade relatada por autores do campo epistemológico. $\mathrm{O}$ primeiro momento refere-se às reuniões dos docentes, no qual todos interagiram, sem hierarquia de disciplinas, para escolher um eixo integrador que norteasse o projeto de forma interdisciplinar. $\mathrm{O}$ segundo momento compreende a apresentação dos trabalhos

\footnotetext{
${ }^{4}$ Entende-se diálogo aqui como a interação dos indivíduos para troca de ideias, onde os mesmos buscam sair das
} fronteiras de sua disciplina para compreender o que é exposto pelo outro. 
pelos alunos para uma banca composta pelos professores integrantes da atividade pedagógica, das diversas disciplinas. Momento este que se observou o empenho de cada professor em compreender o eixo integrador sob a ótica de todas as disciplinas envolvidas.

\section{Sobre o a escolha do Eixo integrador}

Ao retomarmos os conceitos de complexidade de Morin, nos deparamos com um pensamento de Morin (2007) em que o mesmo relata que, após a segunda metade do século XX, a descoberta da Teoria dos Fractais e a Teoria do Caos trouxeram sentido ao conceito de complexidade no meio científico. Na busca de compreender os fenômenos naturais, entendeu-se que a realidade é multidimensional em sua natureza, portanto a escolha do eixo integrador atendeu aos objetivos do projeto, no que se refere a trabalhar os fenômenos naturais em suas múltiplas dimensões, além de ter contribuído para o desenvolvimento do pensamento complexo dos alunos.

Além disso, a escolha do eixo integrador foi bastante coerente para propiciar de forma adequada uma integração de conteúdos. O estudo da geometria dos fractais, por exemplo, nos permite encontrar níveis de integração, aplicações e exemplificações dos conteúdos que se encontram incluídos nas ementas das disciplinas da grade curricular do Ensino Médio. Para exemplificar a proposta de integração das disciplinas, vale a referência de um trabalho realizado pelos alunos participantes deste projeto que retrata o uso dos conhecimentos relativos à determinação da dimensão fractal aplicada à medicina em exames médicos destinados à detecção de células cancerosas. Os alunos explanaram sobre a aplicação notável da Dimensão Fractal através da análise de imagens geradas por uma tomografia computadorizada. Este exame possibilitou aos médicos uma nova visão da anatomia interna do corpo humano, e consequentemente, auxiliar no diagnóstico do câncer com uma identificação mais precisa sobre o estágio de evolução do mesmo. Para expor esse trabalho, os alunos aprofundaram-se em conceitos da biologia sobre a formação de células cancerígenas e em conceitos da matemática sobre o estudo dos logaritmos.

\section{Análises das entrevistas}

Após a intensa análise da leitura das respostas dos entrevistados, emergiram 3 categorias do conteúdo das entrevistas. Para dar início às análises das entrevistas, faz-se 
necessário salientar a fundamentação usada pelos professores participantes do projeto na construção do mesmo. Pois bem, os professores utilizaram como fonte de pesquisa acerca da interdisciplinaridade documentos oficiais da educação, entre eles as Diretrizes Curriculares Nacionais para o Ensino Médio (DCNEM) e os Parâmetros Curriculares Nacionais para o Ensino Média (PCNEM). Esses documentos, por sua vez, não aprofundam o conceito de interdisciplinaridade em um nível mais filosófico. As definições trazidas por esses documentos estão em caráter mais instrumental que epistemológico. Sendo assim, de posse do entendimento da base teórica que os docentes partícipes usaram sobre interdisciplinaridade, algumas características que incitam a interdisciplinaridade, mesmo em seu nível mais elementar, foram observadas e analisadas, visto que, como diz Mello (1999), relatora das DCNEM (BRASIL, 1999): até o nível mais elementar da interdisciplinaridade, denominada interdisciplinaridade singela, é importante, pois ensina ao aluno olhar o mesmo objeto de perspectivas diferentes.

\section{Categoria 1: Concepções dos professores sobre interdisciplinaridade}

Esta categoria baseia-se nos relatos dos entrevistados a partir de como os docentes entendem a concepção de interdisciplinaridade (em nível de integração de conteúdos), e por consequência, de que forma percebem o trabalho interdisciplinar no âmbito escolar, além de compartilharem suas experiências com o tema. Ao serem questionados sobre a concepção de interdisciplinaridade, o entrevistado (P1) declarou: "Acredito que seja a relação entre disciplinas através do trabalho de temas que esteja ligado a elas...”. O entrevistado (P3) disse que "no caso (ambiente escolar) é a relação entre as disciplinas para compreender algum fenômeno, alguma situação...”. O entrevistado (P4) falou: “sistema de interação mútua entre disciplinas a fim de gerar conhecimento consistente e significativo sobre determinado objeto de estudo...".

Segundo Japiassu (1976, p. 67), o entrave maior em relação à interdisciplinaridade se encontra justamente na parte do conceito de interdisciplinaridade. Segundo o autor, "trata-se de um conceito que varia, não somente no nome, mas também naquilo que ele significa (conteúdo)". Portanto, utilizar um conceito capaz de unir todos os epistemólogos, filósofos e educadores em torno de um consenso sobre interdisciplinaridade tornam-se desafiador.

Ainda assim, é possível promover uma reflexão sobre as palavras de alguns autores acerca do tema. Tanto Japiassu (1976) quanto Fazenda (2011), referenciais teóricos importantes no Brasil, que têm na filosofia do sujeito a base de suas teses, apresentam a 
interdisciplinaridade como resposta ao esfacelamento do conhecimento. Para eles a fragmentação é tratada como doença e a interdisciplinaridade seria o tratamento adequado. Para Japiassu (1976), é imprescindível que haja comunicação entre as disciplinas com a finalidade de produzir uma modificação entre elas, através de diálogo compreensível, visto que apenas a troca de informações entre as disciplinas não constitui um método interdisciplinar. Portanto, apenas relacionar disciplinas como mencionado acima por P1, sem que ocorra modificação e enriquecimento mútuo das disciplinas não seria uma prática interdisciplinar na visão epistemológica.

Embora bastante acalorada a discussão acerca da interdisciplinaridade no ambiente filosófico, o que resulta na dificuldade de compreensão do termo por parte dos profissionais da educação, é possível observar uma certa convergência nas respostas analisadas dos professores, uma vez que seus entendimentos se completam no que diz respeito à interdisciplinaridade como ferramenta para proporcionar a compreensão de um objeto ou fenômeno a partir da contribuição e intercomunicação de todas as áreas. Acredita-se que a convergência de respostas se atribui a favor das reuniões que ocorreram para elaboração da atividade, cujo conceito de interdisciplinaridade, na visão pedagógica para projetos escolares, foi bastante discutida com base nos documentos oficiais da educação que trazem o seguinte pensamento:

Na perspectiva escolar, a interdisciplinaridade não tem a pretensão de criar novas disciplinas ou saberes, mas de utilizar os conhecimentos de várias disciplinas para resolver um problema concreto ou compreender um determinado fenômeno sob diferentes pontos de vista. Em suma, a interdisciplinaridade tem uma função instrumental. Trata-se de recorrer a um saber diretamente útil e utilizável para responder às questões e aos problemas sociais contemporâneos (BRASIL, 1999, p. 34 - grifo do autor).

\section{Categoria 2: Interdisciplinaridade como princípio norteador do projeto analisado}

Nesta categoria, evidencia-se a partir dos relatos dos entrevistados como os docentes percebem a presença da interdisciplinaridade na atividade pedagógica analisada. Através das declarações dos professores, observa-se a segurança com que tutelavam a prática da interdisciplinaridade na atividade.

A transcrição de fala do docente (P1): "Na verdade, observei a interdisciplinaridade no momento em que notei maior interação entre alunos e professores, as experiências produzidas a partir do convívio grupal, a união de todos os professores em busca de um objetivo comum, 
que seria a formação dos indivíduos no meio social...”, convergem com o preceitos de Demo (1997) quando este propõe que a atuação interdisciplinar visa reconhecer o que se tem de melhor, realizando em grupo (a prática interdisciplinar). Logo, os atores dos projetos interdisciplinares são tanto os docentes quanto os discentes, devendo o trabalho ocorrer em conjunto para a construção do conhecimento.

Segundo o docente (P2), "a interdisciplinaridade se deu a partir do uso de eixos integradores (geometria fractal e teoria do caos), onde observamos a contextualização dos conteúdos da área das ciências da natureza e da matemática". O docente (P4) concorda com o (P2), "nós utilizamos os fractais para compreender os processos das estruturas naturais, ou seja, os fractais foram nosso eixo integrador como pressupõe interdisciplinaridade". É possível observar o alinhamento das duas falas com as DCEM.

A partir do problema gerador do projeto, que pode ser um experimento, um plano de ação para intervir na realidade ou uma atividade, são identificados os conceitos de cada disciplina que podem contribuir para descrevê-lo, explicá-lo e prever soluções. Dessa forma, o projeto é interdisciplinar na sua concepção, execução e avaliação, e os conceitos utilizados podem ser formalizados, sistematizados e registrados no âmbito das disciplinas que contribuem para o seu desenvolvimento (BRASIL, 1999, p. 89 - grifo do autor).

Os documentos oficiais da educação foram base para elaboração do projeto analisado, o que justifica as respostas dos professores estarem em alinhamento com os mesmos. Contudo, ao analisar os discursos dos professores sobre o uso de eixo integrador para promover a integração de conteúdos, pode-se inferir uma conotação instrumental da interdisciplinaridade, o que pode ir de encontro às concepções epistemológicas de alguns autores.

\section{Categoria 3: A interdisciplinaridade para a aprendizagem significativa}

Nesta categoria, os entrevistados discorrem sobre a importância da interdisciplinaridade nos processos de ensino e de aprendizagem para o exercício de uma prática pedagógica significativa e coerente com a realidade dos alunos. Fazenda (2011) enfatiza que a prática interdisciplinar envolve um trabalho coletivo e participativo que submerge da contextualização dos conteúdos, da valorização do trabalho em grupos, da informação e do capital humano e, ainda, do trabalho com os projetos pedagógicos.

No relato do docente P1 sobre a importância da interdisciplinaridade para a aprendizagem significativa, "contribui bastante na contextualização, além do que deixou a 
aprendizagem escolar mais estimulante e uma experiência social relevante, o aluno ganha uma nova expectativa em relação ao conteúdo, com um domínio maior dos conceitos...”, observase uma consonância com Santomé (1998), quando traz que a motivação para aprender por meio de práticas interdisciplinares é muito grande, pois qualquer problematização do cotidiano pode transformar-se em objeto de estudo.

É possível observar a linearidade do pensamento na fala do docente (P3): “acredito que a interdisciplinaridade amplie a compreensão dos alunos em relação a fatos cotidianos, ao relacionar os conteúdos no intuito de compreender um determinado fenômeno os alunos atribuem significado ao que estão aprendendo...", e do docente P4, “o objetivo geral da interdisciplinaridade é a aprendizagem significativa e esta se dá mediante a conexão das múltiplas disciplinas que ao interagirem esgotam as lacunas cognitivas antes vistas em um estudo fragmentado...". Sabe-se que a tendência à disciplinaridade e a consequente fragmentação de pensamentos foram estimuladas pela necessidade da formação especializada alicerçada em uma pedagogia taylorista-fordista. Esse modelo de educação, como já visto, tem sido alvo de críticas contundentes, pois produz uma racionalidade fragmentadora e poderá gerar as lacunas cognitivas citadas no relato acima do docente (P4).

\section{Considerações finais}

Compreende-se um desafio falar da integração das disciplinas no ambiente escolar, uma vez que há uma grande volatilidade neste tema por partes dos pensadores do meio educacional. Embora bastante discutido em fóruns educacionais e abordados em documentos oficiais da educação, não existe um pensamento consolidado sobre o conceito e aplicação da integração de disciplinas no meio educacional, o que de certa forma contribui para a insegurança dos professores na hora de desenvolver as práticas escolares alicerçadas nesse viés.

Tendo em vista que a preocupação com o ensino mais integrado é uma realidade dos ambientes educacionais, faz-se mister, agora, refletir sobre a contribuições dessa pesquisa acerca do tema. Inicialmente, é necessário entender que todos os projetos elaborados pela Escola lócus de estudo seguem as orientações dadas pelos documentos oficiais da educação, que são a LDB, DCNEM e os PCNEM. Tais documentos tratam a interdisciplinaridade em um caráter mais instrumental e propõem que a mesma ocorra através da integração de conteúdo que promova ao aluno o entendimento de um fenômeno através de diversas visões, e 
que essa forma seja o caminho para a contextualização do ensino. Não se observa, nesses documentos, um aprofundamento na discussão epistemológica do conceito interdisciplinaridade. Sendo assim, para os professores entrevistados, a atividade teve como princípio norteador a integração de conteúdos, pois seguiu as orientações desses documentos. Contudo, encontram-se certas divergências com o pensamento de autores no campo da epistemologia sobre interdisciplinaridade, pois esses alertam para um olhar mais filosófico em relação ao conceito de interdisciplinaridade.

Embora a polissemia encontrada no termo interdisciplinaridade gere algumas dificuldades, infere-se a necessidade de buscar uma prática de integração de conteúdos na prática pedagógica, visto que assumir a integração de disciplinas em sua prática docente permitirá ao professor usar a educação como estratégia humanizadora, capaz de ampliar a consciência dos alunos, corroborando com a construção de novas visões conceituais de conteúdos vistos em sala de aula. Ao buscarmos a origem da palavra educação encontramos dois termos latinos: educare e educere. O primeiro está ligado à transmissão de saberes e fazeres e o segundo está ligado a desenvolver conhecimentos e práticas, além de extrair do aluno aquilo que já está dentro dele. Pois bem, por um longo período, acreditou-se que a base da educação seria apenas o educare, ou seja, a educação tinha apenas a função reprodutora de saberes. Atualmente, pode-se concluir que a educação vai além da simples repetição de conteúdos, na realidade como na etimologia da palavra, a educação também deve ser capaz de desenvolver um sujeito que supere e transforme a sua realidade. Para tanto, é necessário assumir desafios, que envolvem quebra de paradigmas como englobar à atividade docente práticas inter e transdisciplinares associadas ao desenvolvimento do pensamento complexo.

\section{REFERÊNCIAS}

BARBOSA, R. M. Descobrindo a Geometria Fractal para a sala de aula. 3. ed. Belo Horizonte: Autêntica, 2005.

BRASIL. Ministério da Educação. Secretaria de Educação Média e Tecnológica. Parâmetros Curriculares Nacionais: Ensino Médio. Brasília: Ministério da Educação, 2002.

BRASIL. Ministério da Educação. Secretaria de Educação Média e Tecnológica. Diretrizes Curriculares Nacionais: Ensino Médio. Brasília: Ministério da Educação, 1999.

DEMO, P. A Nova L.D.B: |ranços e avanços. 3. Ed. Campinas, SP: Papirus, 1997.

FAZENDA, I. C. A (org.). Práticas interdisciplinares na escola. 12. ed. São Paulo: Cortez, 2011. 
FAZENDA, I. C. A. Interdisciplinaridade: história, teoria e pesquisa. São Paulo: Papirus, 1994.

GATTI, F. G. Administração e Caos: uma estreita relação. Revista de Ciências Gerenciais, São Paulo, v. 11, n. 13, 2007. Disponível em: http://goo.gl/NNqiC. Acesso em: 29 jun. 2012.

JAPIASSU, H. Interdisciplinaridade e patologia do saber. Rio de Janeiro: Ed. IMAGO, 1976.

MORIN, E. A religação dos saberes: o desafio do século XXI. Rio de Janeiro: Bertrand Brasil, 2001

MORIN, E. Introdução ao pensamento complexo. 3. ed. Porto Alegre: Sulina, 2007

SANTOMÉ, J. T. Globalização e interdisciplinaridade: o currículo integrado. Porto Alegre: Artmed, 1998.

\section{Como referenciar este artigo}

ANDRADE, Samara Régia de; MENDE, Marianne Louise Marinho; MESSIAS, Cristhiane Maria Bazílio de Omena. Análise de um projeto pedagógico: fractal e teoria do caos para integração de conteúdos. Revista Ibero-Americana de Estudos em Educação, Araraquara, v. $15, \quad$ n. 1 , p. 206-220, jan./mar. 2020. e-ISSN: 1982-5587. DOI: https://doi.org/10.21723/riaee.v15i1.12263

Submetido em: 16/02/2019

Revisões requeridas: 26/03/2019

Aprovado em: 20/04/2019

Publicado em: 02/01/2020 